\title{
The bioenergy potential for the centre Region of Portugal: the use of biomass as a fuel source
}

\author{
Tanya C.J. Esteves $^{1 *}$, António J.D. Ferreira ${ }^{1}$, José C. Teixeira ${ }^{2}$, Pedro Cabral ${ }^{3}$ \\ ${ }^{1}$ Escola Superior Agrária de Coimbra, Coimbra, Portugal \\ ${ }^{2}$ Universidade do Minho, Guimarães, Portugal \\ ${ }^{3}$ Instituto Superior de Estatística e Gestão de Informação, Lisboa, Portugal \\ * Corresponding author. Tel: +351 239 802940, Fax: +351 239 802979, E-mail: tanya@esac.pt
}

\begin{abstract}
Renewable energy is one of the most effective ways to achieve the sustainability essential for our future. The consumption of fossil fuels is rapidly depleting resources deemed essential for Man's survival.

This work's main focus is to increase bioenergy use in the centre region of Portugal by allying R\&D to facilitate bioenergy availability and distribution throughout the study area.

Accordingly, the available bioenergy potential was important to determine once this knowledge is very limited in the Centre Region of Portugal. Biomass residues for forest stands, burned areas, shrublands and agriculture land uses, municipal solid waste, animal husbandry waste, used vegetable oils, agricultural and food industry and energy crops were the considered material, once they represent great part of the regional available biomass. Additionally, the ideal location for the implementation of the Bioenergy Competency Centre (BCC) was determined, using a GIS approach that considered four scenarios.

Results show the most favorable for the yield of each of the bioenergy sources for bioenergy and that there are minor variations for the BCC best location for the 4 considered scenarios.
\end{abstract}

Keywords: Geographical Information Systems, Bioenergy potential, Land use, Bioenergy resources, Kyoto protocol.

\section{Introduction}

Fossil fuels are extremely attractive as energy sources, once they are relatively easy to distribute, especially oil and gas which are fluids [1]. It is still unknown when cheap fossil fuels will end, but it is estimated that it may happen in just one generation, or even sooner. We currently live what may be considered an oil crisis. Just recently, the price of the barrel of crude oil was above of 135 dollars, whereas in 2004, the price was located at around 35 dollars per barrel [2]. The substantial fluctuation of the oil price may cause serious worldwide economic disruption and lead to protests, as seen recently all around the world [1].

Oil exhaustion is a recurrent subject, with specialists indicating the year that production will reach its peak and when the major oil reserves will finally be depleted [3]. Knowing that fossil fuels will become a rare commodity in the near future, and knowing that humanity is utterly dependant on energy, a new path needs to be traced as to support our energy consuming way of life. Otherwise, serious consequences will outcome from this fact. Sustainability is a key point in today's society, once it involves environmental, social and operational management strategies, an equilibrium that is not easy to control due to their interdependency. According to Boyle [3], a sustainable energy source is ideally one that is not substantially depleted by continued use, does not entail significant pollutant emissions or other environmental problems, and also does not involve the perpetuation of substantial health hazards and/or social injustices. But only a few energy sources come close to this ideal: they are essentially inexhaustible and their use usually entails much lower emissions of GHG or other pollutants, and fewer health hazards [3]. With the use of natural and renewable resources as an alternative to fossil fuels for the production of energy, a higher level of sustainability may be achieved by modern society [4]. The renewables are based on energy flows that are replenished by natural processes, not becoming depleted with use. The environmental impacts 
of renewable energy sources vary, but they are generally much lower than those of conventional fuels [1].

Countries with low or inexistent access to fossil fuels such as Portugal have an elevated price to pay for oil importation: in 2007 the consumption of primary energy from oil represented approximately $54 \%$ of the total [5]. However, Portugal has a final energy consumption per inhabitant that is still low when compared with other EU countries - 1,7 toe/inhabitant against an EU-25 mean of 2,5 toe/inhabitant [6]. Nevertheless, the price raise of fossil fuels represents an exit of a substantial amount of currency to foreign countries, consequently weakening the economy. All together, oil, natural gas and coal represent over $80 \%$ of the Portuguese national energetic balance [5].

Bioenergy is the general term for energy derived from biomass material, such as trees, plants, manure, and sometimes wastes. Such materials can be processed through transformation processes, where the biomass is transformed into biofuels, bioheat or bioelectricity and used for energetic purposes [5, 7]. The renewable energy directive [8] defines biomass as being "the biodegradable fraction of products, wastes and residues from biological origin from agriculture (including vegetable and animal substances), forestry and related industries including fisheries and aquaculture, as well as the biodegradable fraction of industrial and municipal waste" [7].

\subsection{Aim}

Therefore, the first and utmost goal is to analyze the potential of bioenergy for the Centre Region of Portugal for several bioenergy sources, namely from forest stands, burned areas, shrublands and agriculture land uses, municipal solid waste, animal husbandry waste, used vegetable oils, agricultural and food industry and energy crops. To achieve this goal, spatial and non-spatial data is collected, transformed into a comparable energy unit (tonne of oil equivalent - toe) and analyzed in order to evaluate the availability of biomass for energy production throughout the study area.

Having the previously stated information, an analysis of the optimal location for the Bioenergy Competency Centre (BCC) is made. This is an entity that includes a large range of services before and after bioenergy production, such as technical assistance during the production process, research, personnel training and product certification. The adequate implementation of this infra-structure in the terrain is essential for a flourishing development of the use of bioenergy in the study area.

The two overall outcomes of the developed work will be a map of the bioenergy potential for the Centre region of Portugal and a map with recommendations for the optimum location of the implementation of the BCC.

\subsection{Characterization of the study area: the Centre Region of Portugal}

Portugal is geographically located on the European west coast, in the Iberian Peninsula. Is has Spain as boundaries to the North and West and to its West and South, it encounters the Atlantic Ocean. The Centre Region of Portugal is divided into 12 NUTS III areas: Baixo Vouga; Baixo Mondego; Pinhal Litoral; Pinhal Interior Norte; Dão-Lafões; Pinhal Interior Sul; Serra da Estrela; Beira Interior Norte; Beira Interior Sul; Cova da Beira; Oeste and Médio Tejo (Fig. 1). It occupies a total area of $28.200 \mathrm{~km}^{2}, 30,6 \%$ of the country. All these areas comprise a total of 100 municipalities (25,2\% of the countries' total) [9]. According to the 
2001 Census, this region has a population of 2.371 .700 inhabitants, 22,6\% of the Portuguese total, with a population density of 83,5 inhab $/ \mathrm{km}^{2}$ [9].

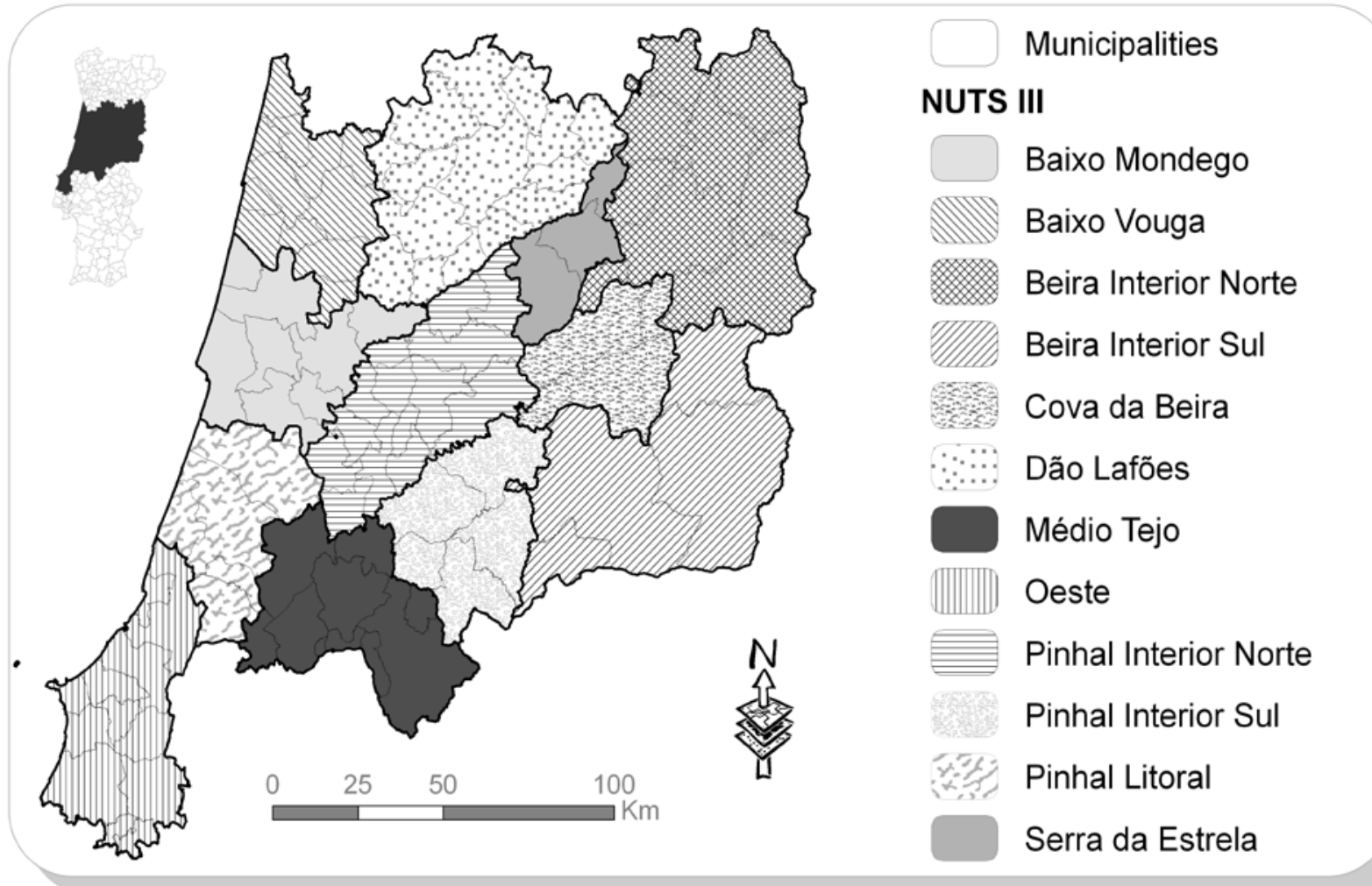

Fig. 1. Study area, the Centre Region of Portugal.

\section{Methodology}

\subsection{The Bioenergy Potential Map for the Centre Region of Portugal}

A primordial step was to join all pertinent information to calculate the amount of the various residues that are passable to be transformed into bioenergy. This extensive research work consisted in using freely available information from several Portuguese organizations that aim to produce both numerical and statistical data for the general public. In what respects to the date of the available information, the most recent data was preferable in opposed to more dated records; nevertheless, some of the gathered information is rather old (e.g., 1999 agricultural census). Regarding to the geographical data, only the Official Administrative Map of Portugal (CAOP) was used [10]. This information uses the European Terrestrial Reference System 89 (ETRS89) coordinate system with a Transverse Mercator projection.

Multiple information was collected and treated for a variety of sources, namely: Forest residue biomass; Agricultural residues biomass; Energetic cultures; Animal husbandry residues; Municipal solid waste; Used vegetable oils; Agricultural and food industries. The collected information was treated as to obtain bioenergy production values in toe. Note that each bioenergy transformation process has a determinate yield for each of the presented residues. However, in this stage of the study, $100 \%$ of the transformation yield was considered.

Afterwards, GIS software was used in order to process all the collected and treated information. For that effect, a model was created which allowed uniting all the information, presenting an output as a final result for the determination of the bioenergy potential of the Centre Region of Portugal. 


\subsection{Location of the Bioenergy Competency Centre}

The BCC will not produce energy itself. Rather, it will have several critical functions for the further development of the bioenergy production area. This Centre will encompass a logical integrated network with the main stakeholders in the Centre Region of Portugal, as to maximize the profitability of the various laboratorial, management and economical infrastructures and available knowledge. Information flow will be crucial in this organism's work processes. Acknowledging the significance of its activities, it should be in a location that is of easy access to all the stakeholders.

For its implementation, several suppositions have to be taken into consideration, some of common sense and others of environmental and legal restraints. As before, all the used information is freely available to the general public. Both alphanumerical and geographical information is used as to achieve the best possible results. This information is collected from several national and international institutes [10, 11, 12, 13, 14]. GIS software was once again used as a valued resource to build this tool.

All the input information is classified into five different classes, being 1 the least preferable condition and 5 the most preferable condition. Four different scenarios are considered in order to verify the applicability of the tool and compare results, where each one varies an input parameter weighting in order to understand its influence on the final result.

\section{Results and Discussion}

\subsection{The Bioenergy Potential Map for the Centre Region of Portugal}

Intermediate results for each of the biomass types have different expressions throughout the territory. Where in some cases, biomass was more prominent in the inland area (e.g., forest biomass), in other cases bioenergy production was more expressive in the littoral area (e.g., animal biomass).

The final result's most influencing component is forest waste biomass. The amount of bioenergy that this source is capable to produce actually overshadows the remaining sources, mainly due to the contribution that forest shrublands make. As an overall result, we verify that the most promising area in terms of bioenergy production is the northern inland area, Beira Interior Norte. This may be due to the combination of climatic factors (e.g., high water availability) with the high amount of rural agricultural and forest areas, leading to a higher biomass yield. The littoral part of the Centre Region of Portugal has significantly lower potential for the production of bioenergy, whereas the middle and Oeste regions of the study area is not at all optimal for production of biomass for bioenergy (Fig. 2).

Shrubland residues aren't correctly handled in most areas, remaining unmanaged in the terrain, hampering greatly the amount of biomass passable to be used. In order to use this material, proper management has to be made in order to guarantee that the full potential can be used for bioenergy, without damaging forest ecosystem equilibrium. Other than yielding bioenergy, another very important consequence would take place, which is the prevention of wildfires, helping to drastically reduce the risk. These ravage the country on a yearly basis leading to important environmental, social and economical losses.

Another consideration may be the analysis of the actual production of bioenergy from some sources. In some cases, using an energy source may be more expensive than not using it (in an 
energetic perspective). In this particular study, it is thought that energy crops are a source of this type, once the amount of produced bioenergy by the different crops is very low, being that their use would be simply impermissible.

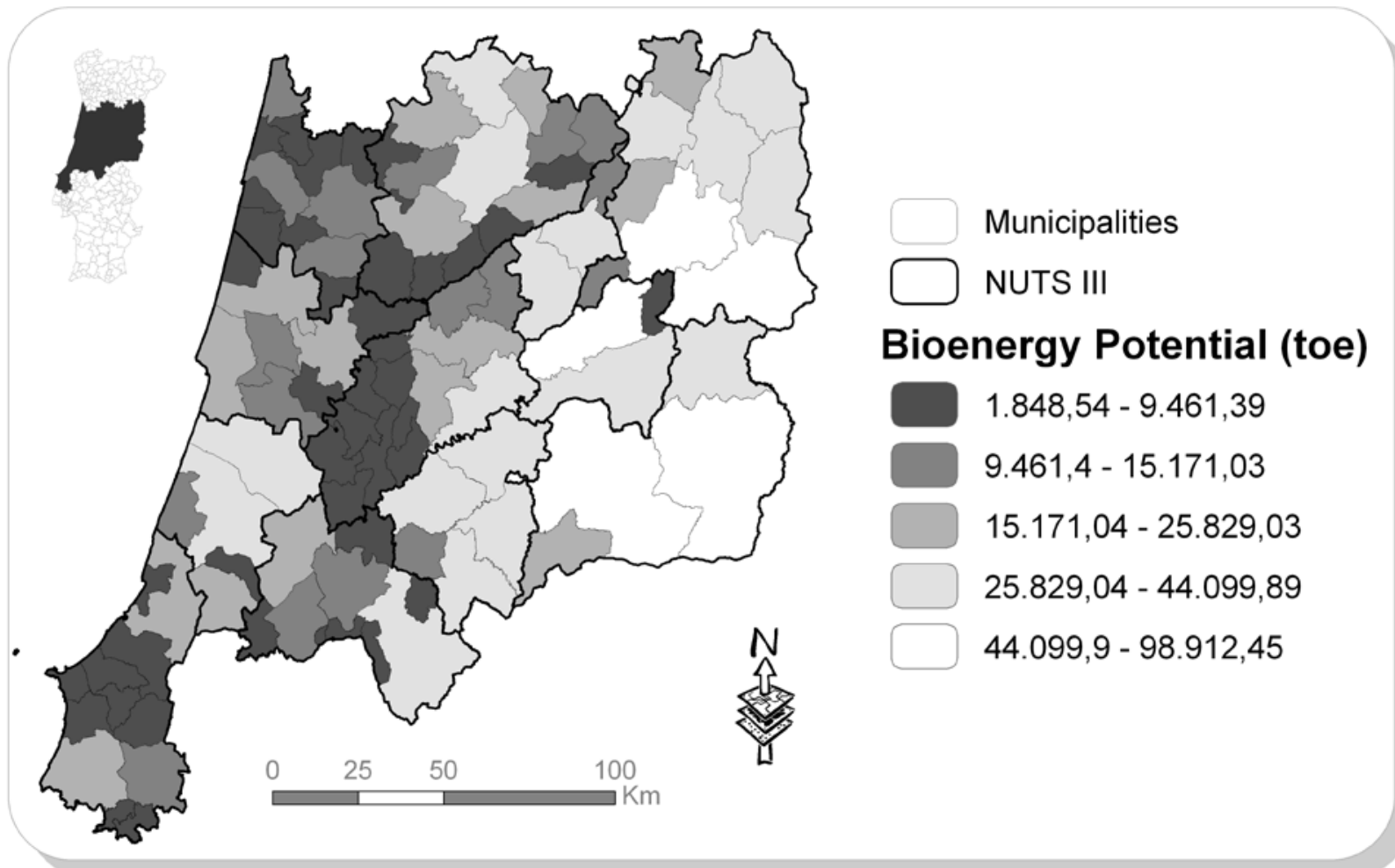

Fig. 2. Bioenergy potential for the Centre Region of Portugal.

\subsection{Location of the Bioenergy Competency Centre}

Properly locating the BCC is of great importance, once it will allow easier access to all stakeholders to the services to be provided by this institution. All inputs are considered key to the location of this institution, once they take into account different aspects that represent reality constraints and allowances. For this study, these are: road types, road distance, travel time, bioenergy potential and slope.

Four different scenarios are traced as to evaluate how different weightings can affect the location of the BCC. For the final map, only values of 4 and 5 are selected. It is also considered that the inputs slope and restrictions have the same weight in each scenario. A delicate balance is used to consider the inputs, and overall, it is thought that the achieved weighting is quite satisfying to construct viable outputs (Fig. 3).

When analyzing the results, at first glance we can verify that they are very similar between them. Most of the locations suggested in the different scenarios are coincident, although with visible changes in the area for every scenario. Another clearly visible result is that there are more areas to implement the BCC with a classification of 4 than with a classification of 5 .

By making a global analysis of all scenarios, we can say that Scenario 2 is the most limitative one, once a lower area with classification 5 is usable. Scenario 3 is the broadest of them, where a higher area is available, although the one with classification 5 is higher in Scenario 1. 
If it were preferable to use only locations with classification 5 , the solution would be almost the same in all scenarios. In general, preferable locations would be situated in the main inland urban municipalities. For the majority of the remaining cases, values vary from scenario to scenario. In most cases, Scenario 3 has the most amount of area for almost all municipalities.

It should be noted that after a final selection of the location for the BCC, it should be confronted with the Municipal Master Plans of the respective municipality. This is a matter of extreme importance, once this legal document will determine the ability or inability to locate the $\mathrm{BCC}$ at a given location.

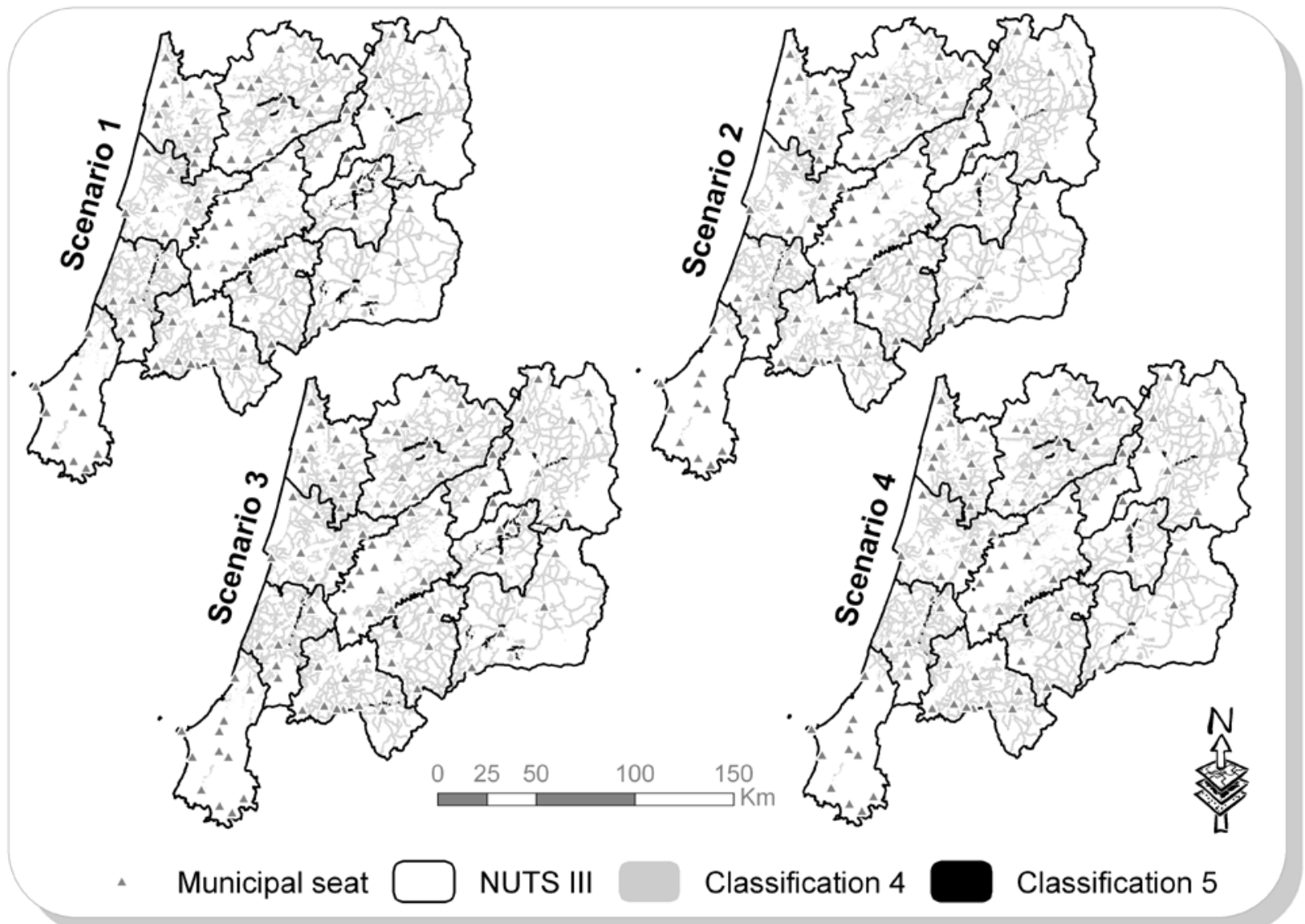

Fig. 3. Scenario results for the location of the Bioenergy Competency Centre.

Picking a specific location for the BCC depends widely on what the directors and main stakeholders are looking for. Do they want more options? Do they want a lesser amount of optimum locations to pick from? Do they only want locations with classification 5 ? Is there no difference in using classification 4 or 5 ? Are they interested in a certain municipality? As like other technologies, GIS and its results are socially constructed via negotiations between various social groups such as developers, practitioners, planners, decision-makers, special interest groups, citizens, and others who may have interest in the planning and policy making process [15]. All these questions have to be weighted by these key actors, mainly by the directors of the future BCC.

An interesting option for the location of the BCC could be the inland area of the country, giving dynamism to this area, once that this population is increasingly fleeing to the littoral, looking for better life conditions. This leads to the abandonment of the land, turning rich soils into inaccessible and unusable terrains for agriculture, forestry, or whichever activity over 
time. This location could very well mean local creation of more jobs, as well as the possibility of awakening the surrounding population to the possibility of this new business and delay (or even mitigate) the abandonment of land.

\section{Conclusions}

The world will soon face an energy problem with the potential to destroy civilizations. It is urgent to seek new energy sources and new management strategies in order to prevail, ones that are optimized and sustainable. So why not use available disposable material and make it work for mankind?

Resources with great promise exist in the Centre Region of Portugal, but one stands out. Forest wastes are a main contributor for the augmentation of the amount of bioenergy that the study area can produce. Another advantage of the use of this material is that it is homogeneously distributed throughout the whole study area, in high amount. The use of this type of material in particular has a double function: the production of bioenergy and the aid in the prevention of forest fires, a yearly affliction for Portugal. As for the other biomass sources presented in this work, they also assume an interesting role in bioenergy production, although not as an important one as forest biomass.

The Centre Region of Portugal has, in general, great potential for the use of biomass for the production of bioenergy. As can be seen in the final results, the interior region of the study area is the one with higher bioenergy potential yield. This fact may bring several consequences to these areas, in which local richness may be enhanced. Reactivating these rural areas and giving them a sustainable way to earn money would greatly help the overall conditions of this population and local environment.

The location of the BCC is the second result from the present study, where the main results point to more adequate areas in the inland area, a highly desirable result. Varying the weights of the input information has little influence regarding the location of the BCC. Favorable results were generally very similar for all the four scenarios. What varied greatly between these scenarios was the amount of available area in each classification.

By having a rather large study area, several particularities of each and every municipality had to be overlooked. This study only presents an initial evaluation of the bioenergy potential, and not an in depth analysis for a given municipality. Regrettably, these small particularities may come to influence the final result of the potential for the municipality. That is why further analyses have to be done as to verify in detail the actual potential for a given municipality.

A strong point of this study is the adaptability of the resulting models. In a fairly easy way, one can open the created tool and alter whatever needed parameters as to meet emerging requirements. This is an extremely important aspect of these tools, once flexible tools accompany the necessary changes in reality throughout time

As to enhance the present study results, some alterations/improvements are necessary in the future, such as introduction of recent information in the modeled tools; consideration of transformation yields of the several bioenergy sources; introduction of other sources of bioenergy present in the study area (e.g., biogas from wastewater treatment plants and industrial sources); and results validation through, e.g., SWOT analysis. 


\section{References}

[1] G. Boyle, B. Everett, and J. Ramage, Energy Systems and Sustainability. Power for a sustainable future. United Kingdom: Oxford University Press, 2004.

[2] U.S. Department of Energy. 2009. Department of Energy. [Online] 2009. http://tonto.eia.doe.gov/oog/info/twip/twipcrvwall.xls\#'Data 2'!A1.

[3] G. Boyle, Renewable energy: power for a sustainable future. 2nd edition. United Kingdom: Oxford University Press, 2004.

[4] J. Richardson, and T.Verwijst, Sustainable bioenergy production systems: environmental, operational and social implications. Biomass and Bioenergy. 2005, Vol. 28, Preface, pp. 95-96.

[5] Direcção Geral de Energia e Geologia. 2005. Direç̧ão Geral de Energia e Geologia Homepage. [Online] 2005. http://www.dgge.pt/.

[6] Agência Portuguesa do Ambiente. 2008. Dossier de Prevenção (redução) de Resíduos Nível mais básico. Amadora: Agência Portuguesa do Ambiente, 2008.

[7] AEBIOM. 2010. European Biomass Association. [Online] 2010. [Cited: 6 May 2010.] http://www.aebiom.org.

[8] European Parliament and of the Council. 2009. Directive 2009/28/CE. Promotion of the use of energy from renewable sources and amending and subsequently repealing Directives 2001/77/EC and 2003/30/EC. s.l., Brussels: Official Journal of the European Communities, 23 April 2009.

[9] AICEP Portugal Global. 2008. Portugal - Perfil país. Lisboa: AICEP Portugal Global, 2008.

[10] Instituto Geográfico Português. 2009. Instituto Geográfico Português. [Online] Grupo de Detecção Remota, 2009. [Cited: 12 September 2009.] http://www.igeo.pt/gdr/.

[11] Instituto da Conservação da Natureza e da Biodiversidade. 2005. Instituto da Conservação da Natureza e da Biodiversidade. [Online] Instituto da Conservação da Natureza e da Biodiversidade, 2005. [Cited: 23 August 2010.] http://portal.icnb.pt/ICNPortal/vPT2007/Valores+Naturais/Informação+Geográfica/.

[12] Instituto Geográfico do Exército. 2010. Instituto Geográfico do Exército. [Online] Instituto Geográfico do Exército, 7 October 2010. [Cited: 7 October 2010.] http://www.igeoe.pt/.

[13]CGIAR - Consortium for Spatial Information. 2008. CGIAR - Consortium for Spatial Information. [Online] CGIAR - Consortium for Spatial Information, 19 August 2008. [Cited: 26 July 2010.] http://srtm.csi.cgiar.org/.

[14]REN. 2010. REN. [Online] REN, 17 August 2010. [Cited: 14 September 2010.] http://www.ren.pt/vPT/Gas/Transporte/tiap/Documents/Rede\%20Nacional\%20de\%20Tra nsporte\%20de\%20Gás\%20Natural\%202010\%20(mapa).jpg.

[15] Malczewski, J. 2004. GIS-based land-use suitability analysis: a critical overview. Progress in Planning. 62, 2004, pp. 3-65. 